\section{$\underset{\substack{\text { hommes } \\ \text { \& migrations }}}{ }$}

\section{Hommes \& migrations}

Revue française de référence sur les dynamiques

migratoires

$1315 \mid 2016$

Ondes de choc

\title{
Virginie Sassoon, Femmes noires sur papier glacé
}

Paris, INA éditions, 2015, 193 p., $20 €$

\section{Catherine Guilyardi}

\section{Q OpenEdition \\ 1 Journals}

\section{Édition électronique}

URL : http://journals.openedition.org/hommesmigrations/3757

DOI : 10.4000/hommesmigrations.3757

ISSN : 2262-3353

\section{Éditeur}

Musée national de l'histoire de l'immigration

\section{Édition imprimée}

Date de publication : 1 juillet 2016

Pagination : 148-149

ISBN : 978-2-919040-36-0

ISSN : 1142-852X

\section{Référence électronique}

Catherine Guilyardi, «Virginie Sassoon, Femmes noires sur papier glacé », Hommes \& migrations [En ligne], 1315 | 2016, mis en ligne le 01 juillet 2016, consulté le 24 septembre 2020. URL : http:// journals.openedition.org/hommesmigrations/3757 ; DOI : https://doi.org/10.4000/ hommesmigrations.3757 
tion et le rôle joué par les migrants. Elle eompare les jardiniers aux nounous et aux domestiques latinos, soulignant comment de nombreux Américains aisés délèguent aux migrants, dans des enditions de travail peu favorables, la prise en charge de larges pans de leurs vies. L'auteure permet d'en savoir plus sur l'existence des migrants latinos et te rôle (thérapeutique ou économique) joué par les jardins dans leur vie. Son analyse, appuyée par une bibliographie solide, est ancrée dans les matériaux empiriques qu'elle donne à voir, sous la forme de portraits et d'extraits d'entre tiens et de terrain, mais aussi de nom breuses photographies et illustrations.
Dans sa conclusion, elle formule une série de propositions pour amorcer une transition vers un modèle plus écolo gique et démocratique, mais aussiplus durable (socialement, économique ment et culturellement). Elle en appelle z̀ la nécessaire volonté politique pour prendre des mesures favorisant l'adop tion de pratiques plus respectueuses de l'environnement et des travailleurs. ta région est, selon elle, un endroit par ticulièrement adapté pour amorcer ce changement, qui y est d'autant plus nécessairequeles défis sociaux, écono miques ou environnementaux y sont plus urgents qu'ailleurs.

tionel Franceut

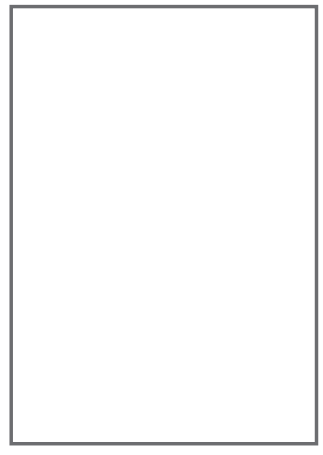

Virginie Sassoon

Femmes noires sur papier glacé

Paris, INA éditions, 2015, 193 p., $20 €$

Issu de sa thèse "Femmes noires sur papier glacé. Les ambiguïtés de la presse féminine noire » soutenue en 2011 à l'Institut français de presse (IFP), ce livre' s'intéresse à un espace situé "dans l'angle mort du modèle républicain, là où la couleur et le sexe séparent les publics", écrit Virginie Sassoon en préambule. Au désintérêt de la recherche pour les médias minoritaires s'ajoute l'indifférence pour la presse féminine "depuis toujours ignorée et méprisée par les intellectuels français ", affirme la sociologue des médias. De cet objet d'étude orphelin, elle a tiré un livre à l'intersection de multiples sujets, des conditions de production des médias minoritaires au marché des produits de beauté " ethniques ", des revendications identitaires aux "oppressions esthétiques", injonctions contradictoires constatées dans les trois magazines qu'elle a étudiés sur une période allant de 2007 à 2009. Leur diffusion en France, en Afrique et aux Antilles-Guyane montre l'existence d'une Atlantique noire francophone et explique la diversité des influences culturelles qui nourrissent ces publications.

Amina, créée au Sénégal en 1972 par Michel de Breteuil, fils d'un ancien éditeur de journaux pour colons, est le titre le plus ancien et le plus connu. Sorte de "catalogue " de portraits de femmes qui ont réussi, de la coiffeuse à la femme de ministre, Amina se vend 
surtout en Afrique. Brune, lancé en 1991 (puis en 2007), est le seul à avoir été fondé par une femme noire, MarieJeanne Serbin-Thomas, mais a une équipe de direction en majorité masculine, comme les deux autres titres. C'est un magazine " haut de gamme " destiné aux femmes actives et plutôt aisées. Miss Ébène, leader en France, a été lancé en 2001. II est destiné aux jeunes femmes qui ont grandi dans l'Hexagone de la classe moyenne.

Traitant de sujets engagés à côté d'autres plus frivoles, porteurs de messages à visée commerciale et rarement d'une parole politique, la presse féminine noire offre-t-elle "une véritable pluralité de modèles d'identification ou réplique-t-elle "en couleur" les critères promus par l'industrie cosmétique et culturelle occidentale?" se demande Virginie Sassoon. L'oppression esthétique qui pèse sur les femmes noires, notamment l'injonction à blanchir leur peau et à lisser leurs cheveux, freine leur émancipation, selon l'auteur, qui montre notamment qu'un quart des publicités dans Amina vante des produits éclaircissants. C'est le seul des trois médias à accepter ce genre de financement, mais les couvertures de Miss Ébène montrent rarement des femmes à la peau très noire et Brune, le plus « militant ", ne choisit pas souvent des femmes qui arborent une coiffure aux cheveux naturellement crépus.

Le contexte est-il favorable à l'émergence d'une identité affichée et assumée pour les femmes noires ? Si la femme blanche doit se battre pour s'affirmer par rapport au groupe dominant qu'est l'homme blanc, être noire c'est aussi porter l'héritage raciste et colonial de la France et de son ancien Empire. "La "beauté blanche" recouvre les traits de l'universel, explique Sassoon, alors que la "beauté noire" apparait particulièrement spécifique, "exotique". " Les féminins noirs donnent peu de clés aux lectrices pour décrypter ce que porte la femme noire. Peutêtre est-ce parce qu'il n'y a pas de féminisme noir en France comme il en existe aux États-Unis, selon Virginie Sassoon. C'est d'ailleurs outre-Atlantique que la presse féminine noire française trouve la plupart de ses « héroïnes ", véritables exemples de réussite. Pour encourager les Noires à définir et affirmer " des critères de beauté "pour soi" ", "un enjeu crucial » selon Virginie Sassoon, la chercheuse préconise la création de plus de supports d'information indépendants et la constitution de groupe de lobbying et de labels de beauté spécialisés. Dans cet essai à la lecture limpide, l'auteure qui s'inscrit dans un champ de recherche en devenir, les Black Studies à la française, conclut : "Les médias des minorités nous invitent à réfléchir aux multiples héritages qui nourrissent le roman national, que la mémoire "officielle" occulte parfois. " Pour que "le pouvoir de raconter des histoires, de les diffuser, de les transmettre et de les ancrer dans la mémoire " n'appartienne pas à la seule majorité. La récente admission d'Alain Mabanckou à la chaire annuelle de création francophone du Collège de France est en ce sens encourageante.

Catherine Guilyardi 